\title{
Increased $N R F 2$ gene (NFE2L2) copy number correlates with mutations in lung squamous cell carcinomas
}

\author{
HIDEFUMI SASAKI, MASAYUKI SHITARA, KEISUKE YOKOTA, YU HIKOSAKA, \\ SATORU MORIYAMA, MOTOKI YANO and YOSHITAKA FUJII \\ Department of Oncology, Immunology and Surgery, Nagoya City University \\ Graduate School of Medical Sciences, Nagoya 467-8601, Japan
}

Received February 2, 2012; Accepted May 15, 2012

DOI: $10.3892 / \mathrm{mmr} .2012 .921$

\begin{abstract}
Nuclear factor (erythroid-derived 2)-like 2 (NRF2) is a transcription factor belonging to the cap ' $n$ ' collar subfamily of the basic-leucine zipper (bZIP) family of transcription factors, which plays a significant role in adaptive responses to oxidative stress. Previously, we reported that NRF2 gene (NFE2L2) mutations correlate with poor prognosis of lung squamous cell carcinomas. We therefore hypothesized that an increased $N R F 2$ gene copy number may correlate with clinicopathological features in lung cancer patients. In this study, the increased copy number of the NRF2 gene was analyzed by realtime polymerase chain reaction (real-time-PCR) amplifications in 90 surgically-treated non-small cell lung cancer (NSCLC) cases. In total, 16 NRF2 mutation cases were included. An increased $N R F 2$ gene copy number was found in $7(7.8 \%)$ lung squamous cell carcinoma patients. Increased NRF2 copy number status significantly correlated with mutation status (mutant, $31.25 \%$ vs. wild-type, 2.7\%; $\mathrm{p}=0.0017$ ). The mean NRF2 gene copy number was significantly higher in mutant (2.478 \pm 0.668$)$ compared to wild-type NRF2 $(1.917 \pm 0.737)$ $(\mathrm{p}=0.0048)$. However, the copy number did not correlate with smoking status $(p=0.3741)$, gender $(p=0.1545)$, age ( $\geq 65$ vs. $<65, \mathrm{p}=0.1237)$ and pathological stage. Although an increased $N R F 2$ copy number correlates with mutations in squamous cell carcinoma, the percentage of the increased copy number was low; therefore, another mechanism may exist for the activation of NRF2 mutations in cancer.
\end{abstract}

\section{Introduction}

Despite recent improvements in diagnosis, lung cancer is a major cause of mortality from malignant diseases, due to

Correspondence to: Dr Hidefumi Sasaki, Department of Immunology, Oncology and Surgery, Nagoya City University Graduate School of Medical Sciences, 1 Kawasumi, Mizuho-cho, Mizuho-ku, Nagoya 467-8601, Japan

E-mail: hisasaki @med.nagoya-cu.ac.jp

Key words: nuclear factor (erythroid-derived 2)-like 2, lung cancer, squamous cell carcinoma, copy number, mutation its high incidence, malignant behavior and the lack of major advancements in treatment strategy (1). Lung cancer was the leading indication for respiratory surgery (42.2\%) in 1998 in Japan (2). More than 15,000 patients underwent surgery at Japanese institutions in 1998 (2). The clinical behavior of lung cancer is largely associated with its stage. The cure of the disease by surgery is only achieved in cases presenting with an early stage of lung cancer (3).

Nuclear factor (erythroid-derived 2)-like 2 (NRF2) is a transcription factor belonging to the cap ' $n$ ' collar subfamily of the basic-leucine zipper (bZIP) family of transcription factors, which plays a significant role in adaptive responses to oxidative stress (4). At the expression level, NRF2 is expressed widely in various human tissues (5), including lung cancer (6). It has been indicated that the overexpression of NRF2 in premalignant cells may enable the cancer cells to survive in an oxidizing tumor environment. Subsequently, the cancer cells alter their metabolic processes, mitochondrial dysfunction and activation of oncogenic signals. It has been shown that patients with lung tumors containing the NRF2 gene (NFE2L2) mutation display a poorer prognosis than patients with non-mutant tumors $(7,8)$. It has been reported that mutations of the NRF2 gene have been associated with primary lung cancer (6-9). $N R F 2$ gene somatic mutation is more common in lung squamous cell carcinomas (7). Recently, NRF2 overexpression was investigated in lung cancer (10-12), and the NRF protein has also been shown to be highly expressed in squamous cell carcinomas of the lung (6).

Although we have previously reported the status of the $N R F 2$ gene (NFE2L2) mutations in lung cancers (7), the association of NRF2 gene copy number status and Japanese lung cancer has not been previously reported. Therefore, in the present study, in order to determine the NRF2 gene copy number status in Japanese lung squamous cell carcinomas, we investigated the copy number by real-time polymerase chain reaction (real-time-PCR) amplifications. The findings were compared to the clinicopathological features of lung squamous cell carcinomas.

\section{Patients and methods}

Patients. The study group included 90 lung squamous cell carcinoma patients who had undergone surgery at the Department of 
Surgery, Nagoya City University Hospital, Nagoya, Japan. All tumor samples were immediately frozen and stored at $-80^{\circ} \mathrm{C}$ until assayed.

The clinical and pathological characteristics of the 90 lung squamous cell carcinoma patients were as follows: 43 cases at stage I, 20 at stage II and 27 at stage III. The mean age was 66.7 years (range, 36-85). Among the 90 lung cancer patients, 35 had lymph node metastasis, 83 were male and 16 had NRF2 gene mutations. The samples from these patients had previously been sequenced for the NRF2 gene (NFE2L2) (7).

PCR assays for NRF2. Genomic DNA was extracted from lung cancer tissues using the Wizard SV Genomic DNA Purification System (Promega, Madison, WI, USA) according to the manufacturer's instructions. DNA concentration was determined by a NanoDrop spectrophotometer (NanoDrop Technologies, Inc. Rockland, DE, USA) and adjusted to a concentration of $2.5 \mathrm{ng} / \mathrm{ml}$. We then used $5 \mu \mathrm{l}$ of each DNA for PCR assays. NRF 2 copy number was analyzed by quantitative real-time PCR, performed using a 7500 Real-Time PCR System (Applied Biosystems, Foster City, CA, USA) by using the QuantiTect SYBR-Green kit (Qiagen Inc., Valencia, CA, USA) (13-15). NRF2 primers used for amplification were: 5'GGTTTCTTCGGCTACGTTT-3' and 5'TAACTCAGGAAT GGATAATAGCTC-3'. Total DNA content was estimated by assaying Line-1 elements for each sample using the primers, 5'-AAAGCCGCTCAACTACATGG-3' and 5'-TGCTTTG AATGCGTCCCAGAG-3'. The cycling conditions were as follows: initial denaturation at $95^{\circ} \mathrm{C}$ for $15 \mathrm{~min}$, followed by 40 cycles at $94^{\circ} \mathrm{C}$ for $15 \mathrm{sec}, 56^{\circ} \mathrm{C}$ for $30 \mathrm{sec}$ and $72^{\circ} \mathrm{C}$ for $34 \mathrm{sec}$. Copy numbers $>3$ were considered as increased, according to previous reports $(13,16,17)$.

Statistical analysis. Statistical analyses were performed using the Mann-Whitney U-test for unpaired samples and Wilcoxon's signed rank test for paired samples. Linear relationships between variables were determined by means of a simple linear regression. Correlation co-efficients were determined by rank correlation using the Spearman's test and $\chi^{2}$ test. The overall survival of the lung cancer patients was examined by the Kaplan-Meier method, and differences were examined by the Log-rank test. All analyses were performed using the Stat-View software package (Abacus Concepts Inc., Berkeley, CA, USA), and a $p$-value $<0.05$ was considered to indicate a statistically significant difference.

\section{Results}

$N R F 2$ gene mutation in Japanese lung cancer. We investigated the NRF2 gene (NFE2L2) mutation status in the N-terminal domain by direct sequencing as previously described (7). In total, 13 out of 109 squamous cell carcinoma patients had $N R F 2$ gene mutations. In addition, we analyzed 39 squamous cell carcinoma patients and 3 had NRF 2 gene mutations. These 3 were known mutations (T80A, W24C, R34Q). In total, 16 out of $148(10.8 \%)$ had NRF2 gene mutations (Fig. 1). All of the mutations were found in squamous cell carcinomas. The $N R F 2$ gene mutations were clustered on exon 2 and resulted in amino acid changes in either the DLG or the ETGE motif of the regulatory Neh2 domain (7).

\section{$\downarrow 101 \mathrm{G}>\mathrm{C}, \mathrm{R} 34 \mathrm{P}(\mathrm{Arg}>\mathrm{Pro})$

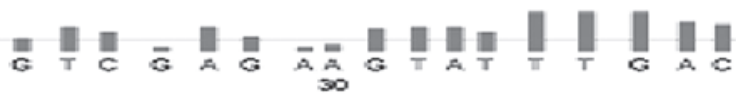

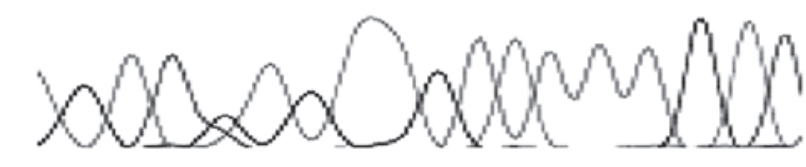

238A>G,T80A(Thy>Ala)
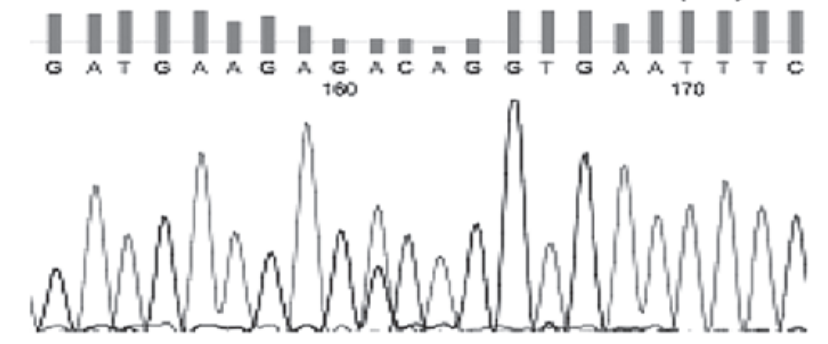

Figure 1. Results from the direct sequencing of the NRF2 gene. Upper panel, $101 \mathrm{G}$ to $\mathrm{A}$ transversion resulted in 34 arginine (Arg) to proline (Pro) conversion (R34P mutation). Lower panel, $238 \mathrm{~A}$ to $\mathrm{G}$ conversion resulted in thyreonine (Thy) to alanine (Ala) conversion (T80A mutation).

NRF2 gene status in Japanese lung cancer patients. Using the primer sets for the $N R F 2$ gene, from 90 lung cancer patients, 7 patients had more than 3 copies of the NRF2 gene and the clinicopathological background is shown in Table I. NRF2 gene copy number status significantly correlated with gene mutations (mutant, $31.25 \%$ vs. wild-type, $2.7 \%$; $\mathrm{p}=0.0017$ ). However, the copy number status did not correlate with smoking status (Brinkman index $<400$ vs. $\geq 400$; $p=0.4443$ ), pathological stage (stage I vs. stage II and III, $\mathrm{p}=0.4375$ ), lymph node metastasis (positive vs. negative, $\mathrm{p}=0.4242)$ or age $(<65$ vs. $\geq 65, \mathrm{p}=0.9999)$. $N R F 2$ gene copy number significantly correlated with gene mutations (mutant, $2.478 \pm 0.668$ vs. wild-type, $1.917 \pm 0.737 ; \mathrm{p}=0.0048$ ). However, the mean $N R F 2$ copy number did not correlate with smoking status (Brinkman index $<400,2.239 \pm 0.499$ vs. $\geq 400,1.998 \pm 0.593$; $p=0.3741$ ), lymph node metastasis (negative, $2.074 \pm 0.567$ vs. positive, $1.926 \pm 0.980 ; \mathrm{p}=0.1695)$, age $(\geq 65,2.083 \pm 0.782$ vs. $<65$, $1.96 \pm 0.732 ; \mathrm{p}=0.1237$ ) or pathological stage.

The overall survival of the 90 lung squamous cell carcinoma patients, with follow-up through to December 31, 2010, was studied in reference to the NRF2 gene status. The survival of the patient with an increased copy number of the NRF2 gene $(\mathrm{n}=7)$ and the patient with a normal copy number of $N R F 2$ $(n=83)$ was not significantly different (Log-rank test, $\mathrm{p}=0.6582$ ).

\section{Discussion}

In our analysis, an increased $N R F 2$ gene copy number was found in $7.8 \%$ of Japanese lung squamous cell carcinomas. The NRF2 gene statuses correlated with NRF2 mutations, indicating that the mutations were activating mutations. 
Table I. Clinicopathological data of the 90 lung squamous cell carcinoma patients.

\begin{tabular}{|c|c|c|c|}
\hline \multirow[b]{2}{*}{ Factors } & \multicolumn{2}{|c|}{ NRF2 gene status } & \multirow[b]{2}{*}{ P-value } \\
\hline & $\begin{array}{c}\text { Number of } \\
\text { patients }\end{array}$ & $\begin{array}{c}\text { Copy } \\
\text { number }\end{array}$ & \\
\hline Mean age (years) & $66.7 \pm 8.4$ & 90 & \\
\hline Pathological stage & & & NS \\
\hline I & $43(47.8 \%)$ & $2.035 \pm 0.490$ & \\
\hline II & $20(22.2 \%)$ & $2.165 \pm 1.033$ & \\
\hline III & $27(30.0 \%)$ & $1.877 \pm 0.859$ & \\
\hline Lymph node metastasis & & & 0.1695 \\
\hline No & $55(61.1 \%)$ & $2.074 \pm 0.567$ & \\
\hline $\mathrm{N}+$ & $35(38.9 \%)$ & $1.926 \pm 0.980$ & \\
\hline BI status & & & 0.3741 \\
\hline$<400$ & $7(7.8 \%)$ & $2.239 \pm 0.499$ & \\
\hline$\geq 400$ & $83(92.2 \%)$ & $1.998 \pm 0.593$ & \\
\hline \multicolumn{4}{|l|}{ Differentiation } \\
\hline Well & $27(30.0 \%)$ & $1.955 \pm 0.817$ & 0.8671 \\
\hline $\begin{array}{l}\text { Moderate/poor } \\
\text { or other }\end{array}$ & $63(70.0 \%)$ & $2.042 \pm 0.729$ & \\
\hline$N R F 2$ mutations & & & 0.0048 \\
\hline Mutant & $16(17.8 \%)$ & $2.478 \pm 0.668$ & \\
\hline Wild-type & $74(82.2 \%)$ & $1.917 \pm 0.737$ & \\
\hline Age, years & & & 0.1237 \\
\hline$\geq 65$ & $41(45.6 \%)$ & $2.083 \pm 0.782$ & \\
\hline$<65$ & $49(54.4 \%)$ & $1.960 \pm 0.732$ & \\
\hline Gender & & & 0.1545 \\
\hline Male & $3(92.2 \%)$ & $1.984 \pm 0.751$ & \\
\hline Female & $7(7.8 \%)$ & $2.404 \pm 0.720$ & \\
\hline
\end{tabular}

*NS, not significant. N0, lymph node metastasis-negative; N+, lymph node metastasis-positive; BI, Brinkman index.

NRF2 (NFE2L2) is a master transcriptional activator of genes encoding many cytoprotective enzymes that are induced in response to environmental and endogenously derived oxidative/electrophilic agents (18-20). A previous report showed that the RNAi-mediated silencing of NRF2 gene expression in nonsmall cell lung cancer inhibited tumor growth (21). A NRF2 gene promoter polymorphism has been identified and has been suggested to correlate with carcinogenesis (22). The association of NRF 2 mutation and increased copy number in lung squamous cell carcinomas suggests a role of NRF 2 in tumorigenesis. The constitutive expression of NRF2 may provide a survival advantage to invasive and metastatic cancer cells, by adaptation to the microenvironment and evolution of chemoresistance in cancer cells under hypoxic conditions $(23,24)$. A previous study showed that the degree of cisplatin (CDDP)-induced DNA crosslinking and the number of cells undergoing apoptosis were increased significantly in A549 cells transfected with NRF2-siRNA (25). The expression of multidrug resistance-associated proteins, the drug efflux proteins, has also been shown to be significantly reduced in NRF2-silenced A549 cells (25). Another study also showed that the inhibition of NRF2 function restored CDDP sensitivity in human ovarian cancer cells (26).

However, in our analysis, more than half of $N R F 2$ gene mutations did not have an increased $N R F 2$ gene copy number. The prognosis analysis between $N R F 2$ gene copy number statuses was not significantly different, which suggests that another mechanism may exist for the activation of NRF2 mutations in cancer. As previously reported, in vitro, wild-type NRF2 was efficiency polyubiqitinated while mutant NRF2 proteins were only weakly polyubiquitinated after treatment with MG132 (8). Wild-type NRF2 protein decreased rapidly, whereas mutant NRF2 proteins were degraded more slowly, having half-lives of approximately twice that of wild-type (8). In addition, mutant NRF2 proteins were significantly more active than wild-type NRF2 by analyzing luciferase activity (8). In addition, the prognostic value of NRF2 expression in lung cancers was controversial. Merikallio et al showed that NRF2 protein expression was correlated with poor prognosis using multi-variate analysis (10). Kim et al showed that high NRF2 expression was not correlated with poor prognosis in stage I lung cancers (27). Interaction between other genes, such as Keap1, would be also important for control of NRF2 expression in NSCLC (28).

\section{Acknowledgements}

The authors would like to thank Mrs. Miki Mochizuki for her excellent technical assistance. This study was supported by Grants-in-Aid for Scientific Research, Japan Society for the Promotion of Science (JSPS) (Nos. 23659674, 24592097 and 21591820) and a grant for cancer research of the Program for developing the supporting system for upgrading education and research (2009) from the Ministry of Education, Culture, Sports, Science and Technology of Japan.

\section{References}

1. Ginsberg RJ, Kris MK and Armstrong JG: Cancer of the lung. In: Principles and Practice of Oncology. 4th edition. Lippincott, Philadelphia, PA, pp673-682, 1993.

2. Yasuda K, Ayabe H, Ide H and Uchida Y: Thoracic and cardiovascular surgery in Japan during 1998. Annual report by the Japanese Association for Thoracic Surgery. Committee of Science. Jpn J Thorac Cardiovasc Surg 48: 401-415, 1998.

3. Postmus PE: Chemotherapy for non-small cell lung cancer: the experience of the Lung Cancer Cooperative Group of the European Organization for Research and Treatment of Cancer. Chest 113 (Suppl 1): 28S-31S, 1998.

4. Kensler TW and Wakabayashi N: Nrf2, friend or foe for chemoprevention? Carcinogenesis 31: 90-99, 2010.

5. Moi P, Chank K, Asunis I, et al: Isolation of NF-E2-related factor 2 (Nrf2), a NF-E2-like basic leucine zipper transcriptional activator that binds to the tandem NF-E2/AP1 repeat of the beta-globin locus control region. Proc Natl Acad Sci USA 91: 9926-9930, 1994.

6. Solis LM, Behrens C, Dong W, et al: Nrf2 and Keap1 abnormalities in non-small cell lung carcinoma and association with clinicopathologic features. Clin Cancer Res 16: 3743-3753, 2010.

7. Sasaki H, Hikosaka Y, Okuda K, et al: NFE2L2 gene mutation in male Japanese squamous cell carcinoma of the lung. J Thorac Oncol 5: 786-789, 2010.

8. Shibata T, Ohta T, Tong KI, et al: Cancer related mutations in Nrf2 impair its recognition by Keap1-Clu3 E3 ligase and promote malignancy. Proc Natl Acad Sci USA 105: 13568-13573, 2008.

9. Hu Y, Ju Y, Lin D, et al: Mutation of the Nrf2 gene in non-small cell lung cancer. Mol Biol Rep 39: 4743-4747, 2012. 
10. Merikallio H, Paakko P, Kinnula VL, et al: Nuclear factor erythroid-derived 2-like 2 (Nrf2) and DJ1 are prognostic factors in lung cancer. Hum Pathol 43: 577-584, 2012.

11. Yang H, Wang W, Zhang Y, et al: The role of NF-E2-related factor 2 in predicting chemoresistance and prognosis in advanced non-small cell lung carcinomas. Clin Lung Cancer 12: 166-171, 2011.

12. Mahaffey CM, Mahaffey NC, Holland W, et al: Aberrant regulation of the MRP3 gene in non-small cell lung carcinoma. J Thorac Oncol 7: 34-39, 2012.

13. Endo K, Sasaki H, Yano M, et al: Evaluation of the epidermal growth factor receptor gene mutation and copy number in non-small cell lung cancer with gefitinib therapy. Oncol Rep 16 : 533-541, 2006.

14. Wang TL, Maierhofer C, Speicher MR, et al: Digital karyotyping. Proc Natl Acad Sci USA 99: 16156-16161, 2002.

15. Zhao X, Weir BA, LaFramboise T, et al: Homozygous deletions and chromosome amplifications in human lung carcinomas revealed by single nucleotide polymorphism array analysis. Cancer Res 65: 5561-5570, 2005.

16. Okuda K, Sasaki H, Yukiue H, et al: Met gene copy number predicts the prognosis for completely resected non-small cell lung cancer. Cancer Sci 99: 2280-2285, 2008.

17. Takano T, Ohe Y, Sakamoto H, et al: Epidermal growth factor receptor gene mutations and increased copy numbers predict gefitinib sensitivity in patients with recurrent non-small-cell lung cancer. J Clin Oncol 23: 6829-6837, 2005.

18. Itoh K, Chiba T, Takahashi S, et al: An Nef2/small Maf heterodimer mediates the induction of phase II detoxifying enzyme genes through antioxidant response elements. Biochem Biophys Res Commun 236: 313-322, 1997.

19. Rushmore TH and Kong AN: Pharmacogenomics, regulation and signaling pathways of phase I and II detoxifying enzymes. Curr Drug Metab 3: 481-490, 2002.
20. Ngyyen T, Yang CS and Pickett CB: The pathways and molecular mechanisms regulating Nrf2 activation in response to chemical stress. Free Radic Biol Med 37: 433-441, 2004.

21. Singh A, Boldin-Adamsky S, Thimmulappa RK, et al: RNAimediated silencing of nuclear factor erythroid-2-related factor 2 gene expression in non-small cell lung cancer inhibits tumor growth and increases efficacy of chemotherapy. Cancer Res 68 7975-7984, 2008

22. Arisawa T, Tahara T, Shibata T, et al: Nrf2 gene promoter polymorphism and gastric carcinogenesis. Hepatogastroenterology 55 750-754, 2008.

23. Semenza GL: HIF-1 for cancer therapy. Nat Rev Cancer 3: 721-732, 2003

24. Zhou J, Scmid T, Schnitzer S, et al: Tumor hypoxia and cancer progression. Cancer Lett 237: 10-21, 2006.

25. Homma S, Ishii Y, Morishima Y, et al: Nrf2 enhances cell proliferation and resistance to anticancer drugs in human lung cancer. Clin Cancer Res 15: 3423-3432, 2009.

26. Cho JM, Manandhar S, Lee HR, et al: Role of Nrf2-antioxidant system in cytotoxicity mediated by anticancer cisplatin: implication to tumor biology. Cancer Lett 260: 96-108, 2008.

27. Kim J-H, Bongner PN, Ramnath N, et al: Elevated peroxiredoxin 1, but not NF-E2-related factor 2, is an independent prognostic factor for disease recurrence and reduced survival in stage I non-small cell lung cancer. Clin Cancer Res 13: 3875-3882, 2007.

28. Ohta T, Iijima K, Miyamoto M, et al: Loss of Keap1 function activates Nrf2 and provides advantages for lung cancer cell growth. Cancer Res 68: 1303-1309, 2008. 